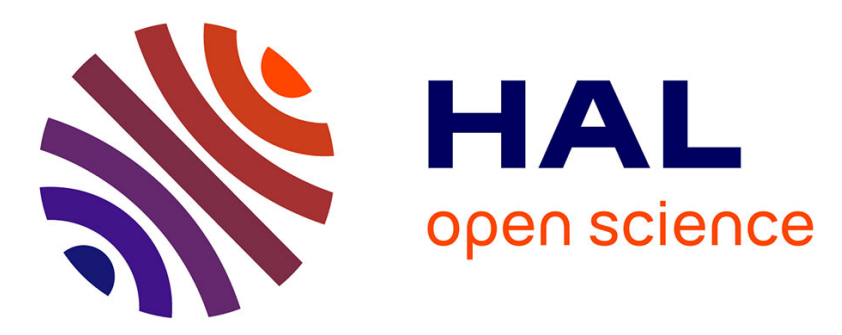

\title{
Small-Signal Modelling for In-Depth Modal Analysis of an MTDC System
}

Samy Akkari, Jing Dai, Marc Petit, Pierre Rault, Xavier Guillaud

\section{To cite this version:}

Samy Akkari, Jing Dai, Marc Petit, Pierre Rault, Xavier Guillaud. Small-Signal Modelling for InDepth Modal Analysis of an MTDC System. 2015 IEEE Electrical Power and Energy Conference (EPEC), Oct 2015, London, Canada. 10.1109/EPEC.2015.7379955 . hal-01244019

HAL Id: hal-01244019

https://hal-centralesupelec.archives-ouvertes.fr/hal-01244019

Submitted on 17 Dec 2015

HAL is a multi-disciplinary open access archive for the deposit and dissemination of scientific research documents, whether they are published or not. The documents may come from teaching and research institutions in France or abroad, or from public or private research centers.
L'archive ouverte pluridisciplinaire HAL, est destinée au dépôt et à la diffusion de documents scientifiques de niveau recherche, publiés ou non, émanant des établissements d'enseignement et de recherche français ou étrangers, des laboratoires publics ou privés. 


\section{Small-Signal Modelling for In-Depth Modal Analysis of an MTDC System}

\author{
S. Akkari, J. Dai, M. Petit \\ Group of Electrical Engineering Paris (GeePs) \\ CentraleSupélec, CNRS UMR 8507, \\ UPSud and UPMC \\ Gif-sur-Yvette, France \\ samy.akkari@centralesupelec.fr
}

\author{
P. Rault \\ Réseau de Transport \\ d'Électricité (RTE) \\ Puteaux, France
}

\author{
X. Guillaud \\ Laboratory of Electrical Engineering \\ and Power Electronics (L2EP Lille) \\ École Centrale of Lille \\ Lille, France
}

\begin{abstract}
In this paper, the state-space model of a VSC-MTDC system is derived from individual components and a modified PI section model for cables is proposed which considers both core and screen conductors as well as their coupling. A modal analysis performed on the complete system reveals the influence of each component on the system modes and permits the identification of a dominant DC voltage mode. This mode has proved to be largely affected by the energy storage level of the DC grid, and to be predominantly influenced by the voltage-droop parameters of the converters, meaning that the $\mathrm{DC}$ voltage dynamic of the MTDC system can be imposed thanks to a judicious choice of the voltage-droop parameters.
\end{abstract}

Index Terms-HVDC, modal analysis, MTDC, state-space model.

\section{INTRODUCTION}

The ever increasing offshore wind energy installed capacity is pushing coastal nations to develop the HVDC technology which is the only feasible solution to transiting large amount of bulk power over long distances. In fact, due to the large capacitance of shielded cables, the capacitive current of an HVAC cable becomes so significant that no power can be delivered above $75 \mathrm{~km}$ [1]. The proliferation of offshore wind farms will most probably give rise to several DC links located in the same geographical zone. DC reinforcements, extensions and $\mathrm{AC}$ zone interconnections may lead to a Multi-Terminal HVDC (MTDC) grid in the future. According to recent publications, the Voltage Source Converter (VSC) is currently the most appropriate and mature technology to interconnect the wind farms and the mainland grids [2]. However, several issues remain to be tackled before meshed HVDC grids become a reality, such as DC fault current extinction (DC breakers), power flow dispatch and DC voltage control. On this last topic, the master-slave control technique used to operate the existing HVDC links is not suitable for meshed HVDC grids [3]. The voltage-droop control technique, described in [4]-[6], seems to be the best solution to safely and efficiently controlling MTDC systems.

Classical small-signal stability analysis, used for modal analysis, is a powerful tool to acquire a better understanding of an MTDC system. This paper first presents the smallsignal modeling of a VSC-HVDC converter and its statespace representation with a similar approach to the one in
[7]. The choice of a model for the DC cables is investigated as well. Then, by associating the multiple state-space models of individual components, the state-space representation of a 5-terminal MTDC system is obtained and studied. In particular, a dominant mode which drives the DC voltage dynamics of the DC grid is identified and traced. The participation factor of each eigenvector is computed in order to study the sensitivity of this DC voltage mode with regards to the other elements of the MTDC system. This mode is linked to the energy storage level of the system and is largely influenced by the value of the voltage-droop parameter of the converters.

The paper is organized as follows. In Section II, the smallsignal modeling of a VSC-HVDC converter is presented and the state-space representations of its elements are obtained. In Section III, the choice of the DC cable model is explained and the state-space representation of the 5-terminal HVDC grid is obtained. Finally, in Section IV, the modal analysis of the MTDC system is performed and the participation factor of each element on the system modes is analyzed.

\section{STATE-Space MOdeling OF A VSC-HVDC CONVERTER}

This section aims at obtaining the state-space model of each part of a VSC-HVDC converter and combining them to generate the model of a full VSC-HVDC converter of the form:

$$
\left\{\begin{aligned}
\frac{d}{d t} x & =A . x+B . u \\
y & =C . x+D . u
\end{aligned}\right.
$$

\section{A. Control strategy of a VSC-HVDC converter}

The global control of the VSC-HVDC converter is depicted in Figure 1. Some of the converters are equipped with a voltage-droop controller in order to participate in the DC voltage control. In fact, a converter equipped with a voltagedroop controller modifies its power reference according to the DC voltage by moving its operating point $\left(P, U_{d c}\right)$ along the characteristic line with a slope of $\frac{1}{k_{v}}$, where $k_{v}$ is the voltagedroop parameter. The converters connected to offshore wind farms are usually not equipped with a voltage-droop controller 
since they inject into the DC grid all the available power regardless of the DC voltage.

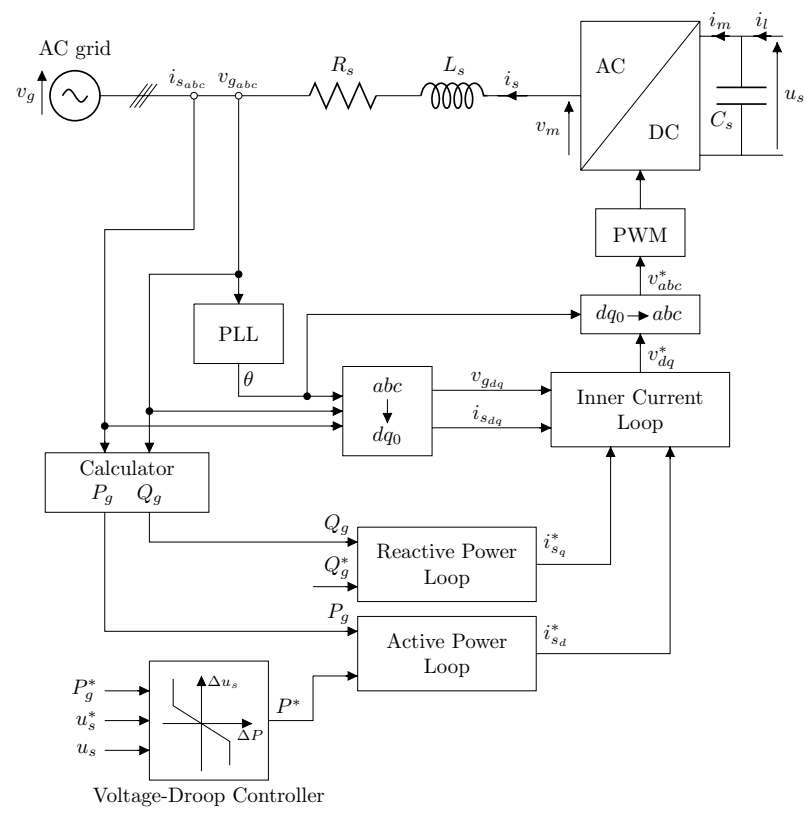

Fig. 1. Control Strategy of a VSC-HVDC converter.

\section{B. Model of the physical system and the current-control loop}

The VSC-HVDC converter, modeled with its current control loop, is the base structure for any VSC model. As shown in Figure 1, the current control is carried out in the $d q 0$ rotating frame. If the switching losses are neglected, the active power on the AC side of the converter matches the power on the DC side of the converter, i.e.

$$
v_{m_{d}} i_{s_{d}}+v_{m_{q}} i_{s_{q}}=u_{s} i_{m}
$$

This non-linear equation is linearized by using the first order Taylor series. With each quantity composed of an operating point (denoted by the capital letter and the subscript 0) and a small variation (denoted by the Greek letter $\Delta$ ), Equation (2) can be linearized as:

$$
\Delta v_{m_{d}} I_{s_{d_{0}}}+\Delta i_{s_{d}} V_{m_{d_{0}}}+\Delta v_{m_{q}} I_{s_{q_{0}}}+\Delta i_{s_{q}} V_{m_{q_{0}}}=\Delta u_{s} I_{m_{0}}+\Delta i_{m} U_{s_{0}}
$$

The linearized current loop, the physical system on the AC side of the converter as well as the physical system on the DC side of the converter are depicted in Figure 2 (more details in [6], [8], [9]), where $x_{i_{d}}$ and $x_{i_{q}}$ are the outputs of the integral part of the controllers corresponding respectively to the d-axis and q-axis projection of the $d q 0$ frame.

From Figure 2, the state-space model of the currentcontrolled VSC is obtained, whose inputs are the current references in the $d q 0$ frame, the DC voltage and the d-axis projection of the AC grid voltage, and whose outputs are the $\mathrm{AC}$ currents in the $d q 0$ frame and the DC current.

\section{Outer loop model}

1) Active and reactive power loops: If the $d q 0$ frame is chosen such that $v_{g_{q}}=0$, the active power injected or extracted from the $\mathrm{AC}$ grid is:

$$
p_{g}=v_{g_{d}} i_{s_{d}}
$$

where a positive $p_{g}$ corresponds to power extracted from the DC grid and injected into the AC grid. The outer loop giving the d-axis current reference of a VSC is the active power controller potentially combined with a voltage-droop controller.

Equation (4) can be linearized as:

$$
\Delta p_{g}=\Delta v_{g_{d}} I_{s_{d_{0}}}+\Delta i_{s_{d}} V_{g_{d_{0}}}
$$

The block diagram of the active power loop is depicted in Figure 3, where $x_{p}$ is the output of the integral controller. For more information about the feed-forward choice, see [10].

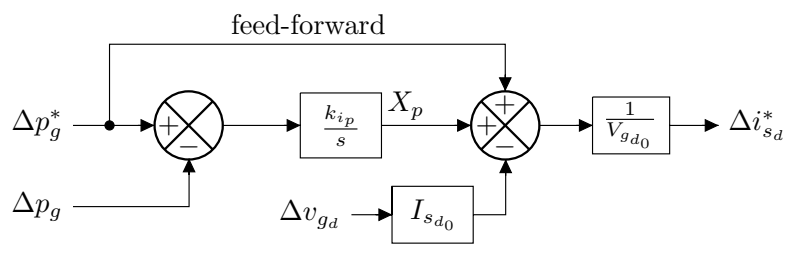

Fig. 3. Linearized active power loop.

The state-space model of the active power loop can be obtained from Figure 3.

It is assumed that the q-axis current reference is provided by a reactive power controller. Since the reactive power loop has the same structure as the active power loop with the exception of a negative sign ( since $q_{g}=-v_{g_{d}} i_{s_{q}}$ ), the reactive power loop state-space model is similar to that of the active power loop and is not further detailed here.

2) Voltage-droop controller: Some converters are also equipped with the voltage-droop controller [4], [11] depicted in Figure 4. This controller modifies the active power reference $\Delta p_{g}^{*}$ of the active power loop of Figure 3 .

This additional loop slightly alters the state-space model of the d-axis outer loop of the converter since it adds two additional inputs, $\Delta u_{s}^{*}$ and $\Delta u_{s}$, such that the new active power reference $\Delta p_{g_{v}}^{*}$ of the active power loop obeys:

$$
\Delta p_{g_{v}}^{*}=\Delta p_{g_{v}}+\frac{1}{k_{v}}\left(\Delta u_{s}-\Delta u_{s}^{*}\right)
$$

\section{State-Space MOdeling OF The 5-Terminal HVDC GRID}

\section{A. DC cable model}

Each DC line consists of two unipolar shielded cables (a positive and a negative pole), as shown in Figure 5, where cable screens are grounded at each end.

Initially, the DC cables were modeled by a classical PI equivalent, without taking into account the cable shields. However, replacing the classical PI equivalent model with the 


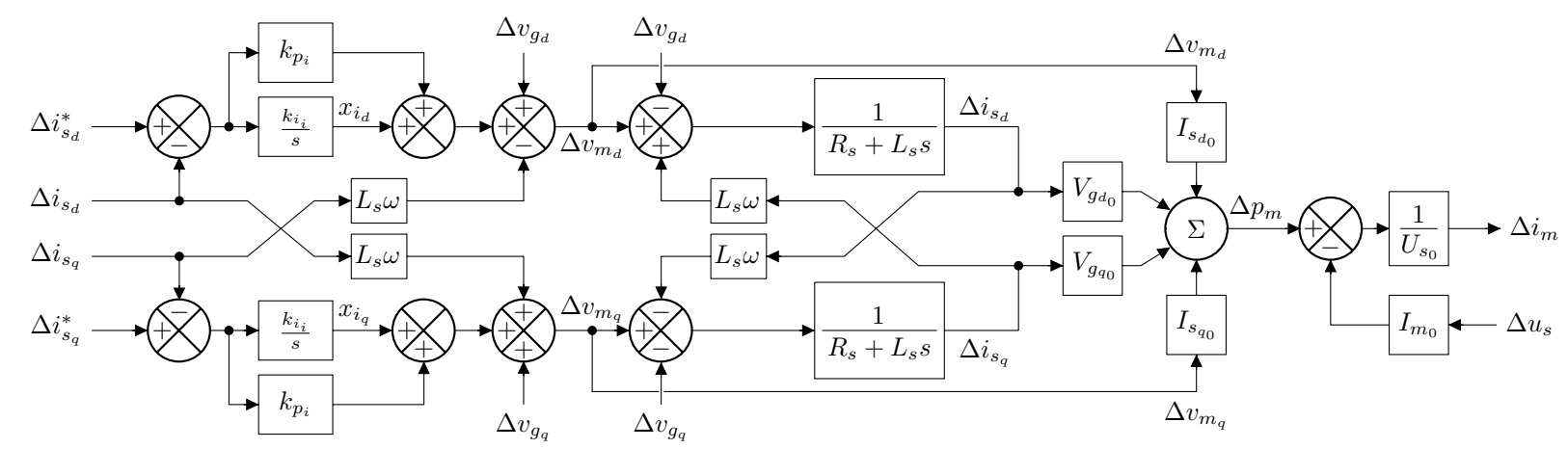

Fig. 2. Linearized model of the current-controlled VSC.

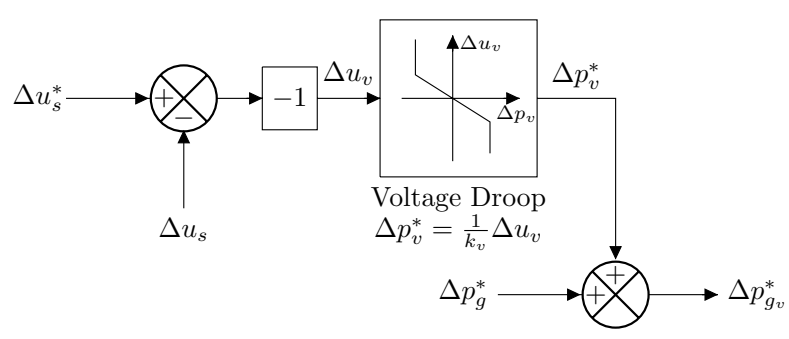

Fig. 4. Linearized voltage-droop controller.

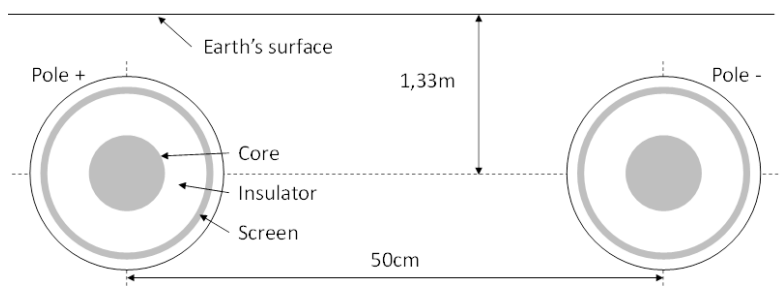

Fig. 5. DC lines layout.

more complicated but much more accurate wide-band model [12] noticeably impacts the DC voltage dynamics. This is illustrated in Figure 6, where the DC cable model's impacts on the DC voltage dynamics are compared in EMTP-RV. It appears that the classical PI equivalent model produces undesirable oscillations, which do not exist with the wideband model.

In-depth investigations revealed that the current flowing through the screen conductor is actually an important source of damping of the DC voltage. Therefore, a modified PI section model including both core and screen conductors as well as their coupling (modeled by a mutual inductance between these two conductors, as depicted in Figure 7 for the positive pole of the DC cable), have to be considered in order to acquire a more accurate model of the DC cable yet much simpler than the wide-band model.

Figure 6 shows that the response of this new model (called coupled PI equivalent model) is very close to the wide-band model reference. This validates the use of this DC cable model.

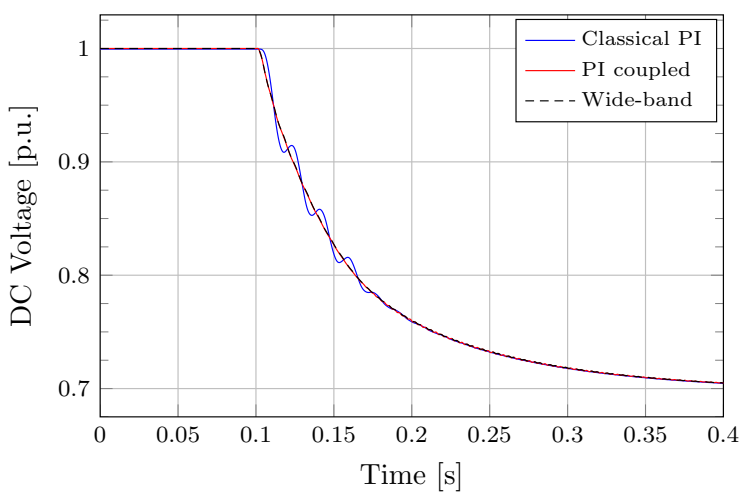

Fig. 6. EMTP-RV simulation showing the impact of a power decrease on the DC voltage dynamics of different DC cable models.

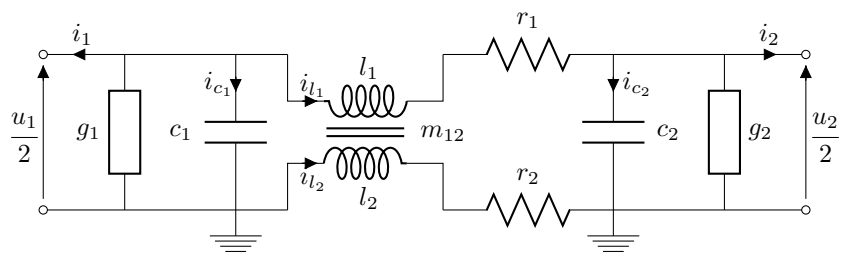

Fig. 7. Positive pole of the PI core-screen coupled model.

According to Figure 7, the Kirchhoff current law gives:

$$
i_{c_{1}}=-i_{1}-i_{l_{1}}-g_{1} \frac{u_{1}}{2} \quad i_{c_{2}}=-i_{2}+i_{l_{1}}-g_{2} \frac{u_{2}}{2}
$$

the Kirchhoff voltage law gives:

$$
u_{l_{1}}=\frac{u_{1}}{2}-\frac{u_{2}}{2}-r_{1} i_{l_{1}} \quad u_{l_{2}}=-r_{2} i_{l_{2}}
$$

and the evolution of the inductance currents and capacitor voltages obeys:

$$
\begin{gathered}
\frac{d u_{c_{1}}}{d t}=\frac{1}{c_{1}} i_{c_{1}} \quad \frac{d u_{c_{2}}}{d t}=\frac{1}{c_{2}} i_{c_{2}} \\
\Phi_{1}=l_{1} i_{l_{1}}+m_{12} i_{l_{2}} \quad \Phi_{2}=l_{2} i_{l_{2}}+m_{12} i_{l_{1}} \\
u_{l_{1}}=\frac{d \Phi_{1}}{d t}=l_{1} \frac{d i_{l_{1}}}{d t}+m_{12} \frac{d i_{l_{2}}}{d t} \\
u_{l_{2}}=\frac{d \Phi_{2}}{d t}=l_{2} \frac{d i_{l_{2}}}{d t}+m_{12} \frac{d i_{l_{1}}}{d t}
\end{gathered}
$$


which yields:

$$
\begin{aligned}
\frac{d i_{l_{1}}}{d t} & =\frac{l_{2} u_{l_{1}}}{l_{1} l_{2}-m_{12}^{2}}-\frac{m_{12} u_{l_{2}}}{l_{1} l_{2}-m_{12}^{2}} \\
\frac{d i_{l_{2}}}{d t} & =\frac{l_{1} u_{l_{2}}}{l_{1} l_{2}-m_{12}^{2}}-\frac{m_{12} u_{l_{1}}}{l_{1} l_{2}-m_{12}^{2}}
\end{aligned}
$$

These equations give the state-space model of a DC line where the output voltage of Figure 7 is simply multiplied by 2 since each pole has the same length and the same characteristics.

\section{B. 5-Terminal HVDC grid model}

The studied system is a 5-terminal HVDC grid interconnecting two offshore wind farms and three asynchronous AC grids as depicted in Figure 8. The parameters of the MTDC system are listed in Appendix.

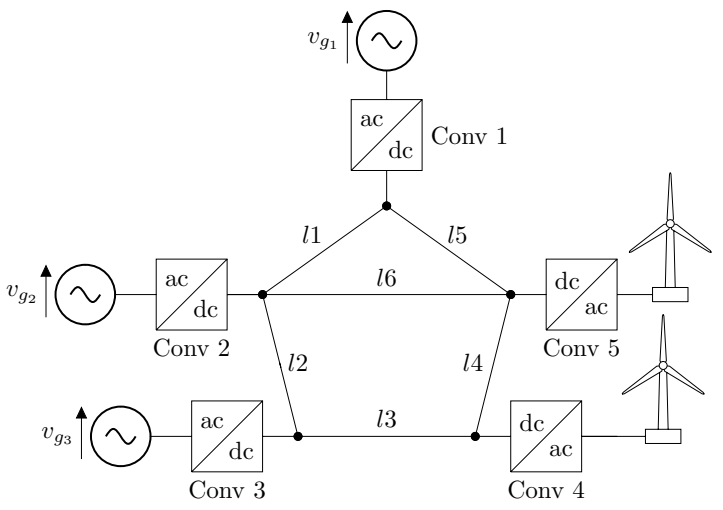

Fig. 8. Topology of the HVDC grid.

Converters 1, 2 and 3 are equipped with voltage-droop controllers whereas converters 4 and 5 are equipped with regular active-power loops since they are connected to offshore wind-farms and inject all the power harvested by the windfarms into the DC grid. The initial power operating point of each VSC-HVDC converter as well as their voltage-droop coefficients ${ }^{1}$ are shown in Table I.

TABLE I

POWER REFERENCE VALUES AND VOLTAGE-DROOP COEFFICIENTS OF THE VSC-HVDC CONVERTERS

\begin{tabular}{|c|c|c|c|c|c|}
\hline Converter & $\mathbf{1}$ & $\mathbf{2}$ & $\mathbf{3}$ & $\mathbf{4}$ & $\mathbf{5}$ \\
\hline$P_{g}^{*}$ (MW) & 200 & 200 & -50 & -162 & -200 \\
\hline$k_{v}$ (p.u.) & -0.4834 & -0.4834 & -0.4834 & $-\infty$ & $-\infty$ \\
\hline
\end{tabular}

The global state-space model of the full MTDC system is obtained by summing the cable and station capacitors at the connection nodes and by combining the multiple state-space models [14], as shown in Figure 9. The final state-space model of the complete MTDC system consists of a 60x1 input vector, a $42 \times 1$ output vector, a $47 \times 1$ state vector, a $47 \times 47$ A matrix, a $47 \times 60$ B matrix, a $42 \times 47 \mathrm{C}$ matrix and a $42 \times 60 \mathrm{D}$ matrix.

\footnotetext{
${ }^{1}$ The voltage-droop parameter values were computed to achieve a time response of $100 \mathrm{~ms}$, see [13] for more information.
}

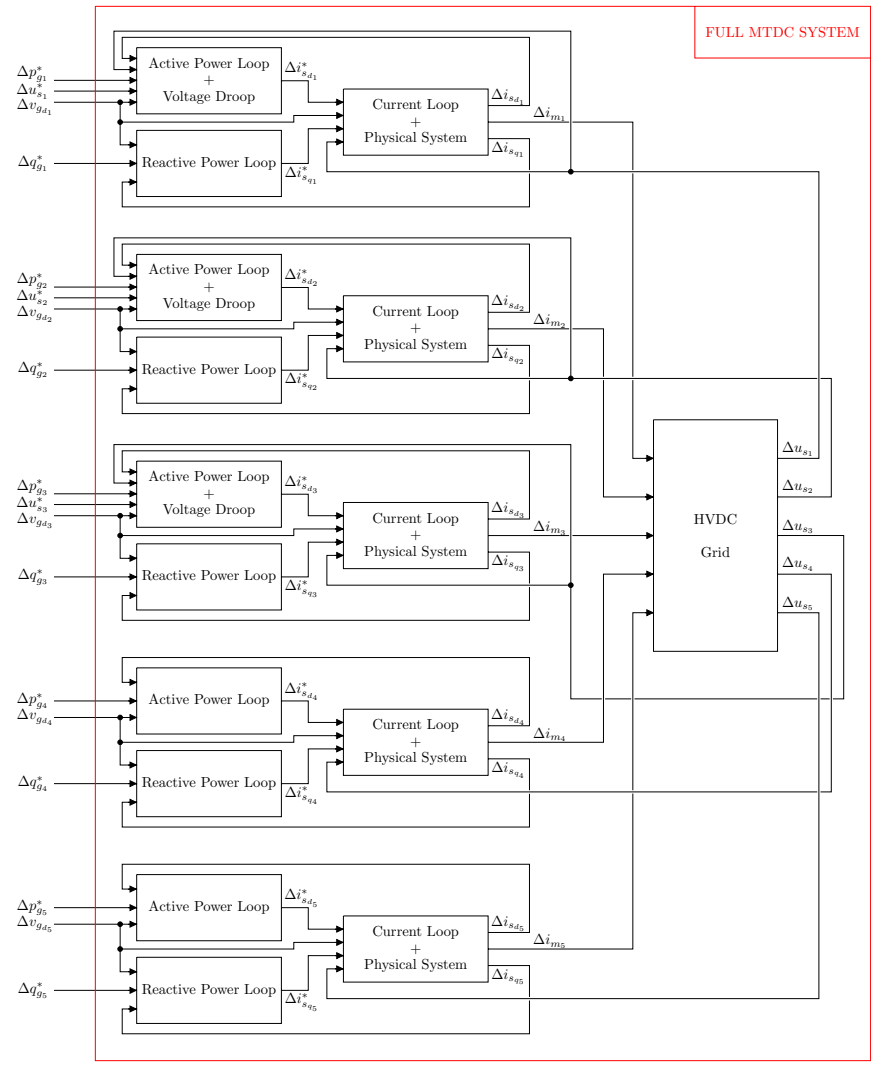

Fig. 9. System association scheme used for the state-space representation of the 5-terminal MTDC system.

\section{Modal Analysis OF THE 5-Terminal HVDC GRID}

A modal analysis can now be performed on the final statespace model of the 5-terminal HVDC grid presented in Figure 8. Table II summarizes its eigenvalues and indicates the relative participation of the state variables to the different modes (corresponding to their respective eigenvalues), quantified by the state variables participation factors [15].

The 47 modes (size of the state vector) are divided into two distinct groups. The first group is associated to the DC grid $\left(\lambda_{d c_{1, \ldots, 16}}\right)$ while the second group corresponds to those associated to the VSCs $\left(\lambda_{c_{1, \ldots, 31}}\right)$ :

- Modes associated to the eigenvalues from $\lambda_{d c_{1}}$ to $\lambda_{d c_{8}}$ are mostly affected by the elements of the DC grid but are also influenced by the parameters of the active power loops (state variable $x_{p}$ ) of the three converters equipped with a voltage-droop controller.

- Modes associated to the eigenvalues from $\lambda_{d c_{9}}$ to $\lambda_{d c_{16}}$ depend on the topology of the HVDC grid and are exclusively affected by the elements of the DC cables. These modes can be identified in the state-matrix of the HVDC grid alone (without the converters).

- Modes associated to the eigenvalues from $\lambda_{c_{1}}$ to $\lambda_{c_{14}}$ correspond to those inner current loops (state variable $x_{i_{q}}$ for the $q$-axis, $x_{i_{d}}$ for the $d$-axis) of the converters whose outer loops (state variable $x_{q}$ for the reactive power loop, $x_{p}$ for the active power loop) are not impacted by the 
TABLE II

MODAl ANALYSIS OF THE 5-TERMINAL HVDC GRID

\begin{tabular}{|c|c|c|c|c|c|}
\hline \multicolumn{3}{|c|}{ Eigenvalues } & $\begin{array}{c}\text { Freq. } \\
(\mathrm{Hz})\end{array}$ & $\begin{array}{c}\text { Damp. } \\
\text { ratio }\end{array}$ & Dominant states \\
\hline \multirow{9}{*}{ 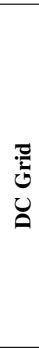 } & $\lambda_{d c_{1,2}}$ & $-56.7 \pm j 1028$ & 164 & 0.055 & \multirow{3}{*}{$\begin{array}{c}x_{p_{1}}, x_{p_{2}}, x_{p_{3}} \\
\Delta u_{s_{1}}, \Delta u_{s_{2}}, \Delta u_{s_{3}} \\
\Delta u_{s_{4}}, \Delta u_{s_{5}}\end{array}$} \\
\hline & $\lambda_{d c_{2,3}}$ & $-56.9 \pm j 995$ & 158 & 0.057 & \\
\hline & $\lambda_{d c_{5,6}, 6}$ & $-57.1 \pm j 724$ & 115 & 0.079 & \\
\hline & $\lambda_{d c_{7,8}}$ & $-57.7 \pm j 635$ & 101 & 0.090 & $\begin{array}{c}i_{l_{1_{1}}}, i_{l_{2_{1}}}, i_{l_{1_{4}}}, \\
i_{l_{2_{4}}}, i_{l_{1_{5}}}, i_{l_{2_{5}}}, \\
\Delta u_{s_{1}}, \Delta u_{s_{2}} \\
\Delta u_{s_{3}}, \Delta u_{s_{4}}, \Delta u_{s_{5}}\end{array}$ \\
\hline & $\lambda_{d c_{9,10}}$ & -117.1 & - & - & \multirow{5}{*}{$\begin{array}{l}i_{l_{1_{1}}}, i_{l_{21}}, i_{l_{1_{2}}}, \\
i_{l_{2_{2}}}, i_{l_{1_{3}}}, i_{l_{2_{3}}}, \\
i_{l_{1_{4}}}, i_{l_{2_{4}}}, i_{l_{1_{5}}} \\
i_{l_{1_{4}}}, i_{l_{2_{4}}}, i_{l_{1_{5}}} \\
i_{l_{2_{5}}}, i_{l_{1_{6}}}, i_{l_{2_{6}}}, \\
\end{array}$} \\
\hline & $\lambda_{d c_{11,12}}$ & -4.47 & - & - & \\
\hline & $\lambda_{d c_{13}}$ & -4.45 & - & - & \\
\hline & $\lambda_{d c_{14}}$ & -4.49 & - & - & \\
\hline & $\lambda_{d c_{15,16}}$ & -0.604 & - & - & \\
\hline \multirow{6}{*}{ 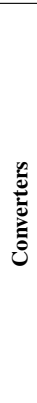 } & $\lambda_{c_{1} \ldots 14}$ & $-195.2 \pm j 230$ & 37 & 0.650 & $\begin{array}{c}x_{q_{1} \ldots 5}, x_{i_{q_{1} \ldots 5}}, \\
x_{p_{4}}, x_{p_{5}}, \\
x_{i_{d_{4}}}, x_{i_{d_{5}}}\end{array}$ \\
\hline & $\lambda_{c_{15} \ldots 18}$ & $-193.8 \pm j 226$ & 36 & 0.650 & \multirow{3}{*}{$\begin{array}{c}\Delta u_{s_{1}}, \Delta u_{s_{2}}, \\
\Delta u_{s_{3}}, \Delta u_{s_{4}}, \Delta u_{s_{5}}, \\
x_{i_{d_{1}}}, x_{i_{d_{2}}}, x_{i_{d_{3}}}, \\
x_{i_{d_{4}}}, x_{i_{d_{5}}}, \\
i_{l_{1_{1}}}, i_{l_{2_{1}}}, i_{l_{1_{2}}}, \\
i_{l_{2_{2}}}, i_{l_{1_{3}}}, i_{l_{2_{3}}}, \\
i_{l_{1_{4}}}, i_{l_{l_{4}}}, i_{l_{1_{5}}}, \\
i_{l_{1_{4}}}, i_{l_{2_{2}}}, i_{l_{1_{5}}}, \\
i_{l_{2_{5}}}, i_{l_{l_{6}}}, i_{l_{2_{6}}}\end{array}$} \\
\hline & $\lambda_{c_{19,20}}$ & $-184.0 \pm j 238$ & 38 & 0.611 & \\
\hline & $\lambda_{c_{21}}$ & -22.6 & - & - & \\
\hline & $\lambda_{c_{22}}$ & -28.8 & - & - & $\Delta i_{s_{d_{1} \ldots 3}}$ \\
\hline & $\lambda_{c_{23 \ldots 31}}$ & -29.7 & - & - & $\Delta i_{s_{d_{1} \ldots 5}}, \Delta i_{s_{q_{1} \ldots 5}}$ \\
\hline
\end{tabular}

behavior of the MTDC system. In fact, the reactive power loops of all five converters, as well as the active power loops of converters 4 and 5, are independent of the MTDC system since their output remains invariably constant. As anticipated, the eigenvalues of these modes correspond to the dynamics of the inner current loops (tuned for a response time of $15 \mathrm{~ms}$ ).

- Contrary to the eigenvalues from $\lambda_{c_{1}}$ to $\lambda_{c_{14}}$, modes associated to the eigenvalues from $\lambda_{c_{15}}$ to $\lambda_{c_{20}}$ correspond to the inner current loops ( $d$ and $q$-axis) of the three converters whose active power loops are highly impacted by the behavior of the MTDC system through the DC voltage droop. In particular, the modes associated to the conjugate eigenvalue pair $\lambda_{c_{19}}$ and $\lambda_{c_{20}}$ correspond to complex interactions between the voltage-droop controllers of converters 1 to 3 , the converters' inner current loops and the DC grid. Those two modes describe the dynamic of the DC current in the whole MTDC system. While the eigenvalues $\lambda_{c_{15}}$ to $\lambda_{c_{18}}$ coincide with the dynamics of the inner current loops (tuned for a response time of $15 \mathrm{~ms}$ ), the modes associated to the conjugate eigenvalue pair $\lambda_{c_{19}}$ and $\lambda_{c_{20}}$ are coupled to the DC voltage dynamics and are highly volatile with regards to the voltage-droop parameter, as shown in Figure 10, where the root locus of the state matrix A are shown for different voltage-droop gains ranging from 0 to 0.5 p.u.

- Similar to the modes associated to $\lambda_{c_{19}}$ and $\lambda_{c_{20}}$, the mode associated to the eigenvalue $\lambda_{c_{21}}$ corresponds to complex interactions between the voltage-droop controllers of converters 1 to 3 , the converters' inner current loops and the DC grid. However, contrary to the DC current modes (associated to the conjugate eigenvalue pair $\lambda_{c_{19}}$ and $\lambda_{c_{20}}$ ), this single mode describes the dy- namic of the DC voltage in the whole MTDC system. Despite the fact that the voltage-droop parameters were originally tuned to achieve a DC voltage response time of $100 \mathrm{~ms}$ (tuning which does not take into account the energy storage level of the DC grid, see [10] for more details), the interaction between the DC cables capacitors and the VSCs modifies the overall dynamics of this mode to give a response time of $130 \mathrm{~ms}$, which shows that the DC voltage dynamic is impacted by the energy storage level of the DC grid. As shown in Figure 10, because of the coupling between the DC current modes (associated to the conjugate eigenvalue pair $\lambda_{c_{19}}$ and $\lambda_{c_{20}}$ ) and the DC voltage mode, the eigenvalue pair $\lambda_{c_{19}}$ and $\lambda_{c_{20}}$ moves to the left with higher values of the droop gain while the eigenvalue $\lambda_{c_{21}}$ moves to the right with higher values of the droop gain.

- Modes associated to the eigenvalues from $\lambda_{c_{22}}$ to $\lambda_{c_{31}}$ correspond to the converters' outer loops used to compute the current references of the inner current loops. As expected, the modes associated to these eigenvalues have dynamics corresponding to the outer loops (tuned for a $100 \mathrm{~ms}$ response time). In particular, the mode associated to the eigenvalue $\lambda_{c_{22}}$ corresponds to the additional active power injected or withdrawn from the DC grid by the converters equipped with a voltage-droop controller.

The root locus of Figure 10 indicates that the DC voltage response time can range from $15 \mathrm{~ms}$ (corresponding to voltagedroop parameters close to 0.001 p.u.) to $150 \mathrm{~ms}$ (corresponding to voltage-droop parameters close to 0.5 p.u.) since the eigenvalue $\lambda_{c_{21}}$ ranges from -225 to -20 . This shows that the DC voltage mode is largely influenced by the voltage-droop parameters of the converters, and more importantly, that a finetuning of the voltage-droop parameters enables the selection of any desired response time for the DC voltage dynamic between 15 to $150 \mathrm{~ms}$, as long as the storage level of the DC grid remains unchanged.

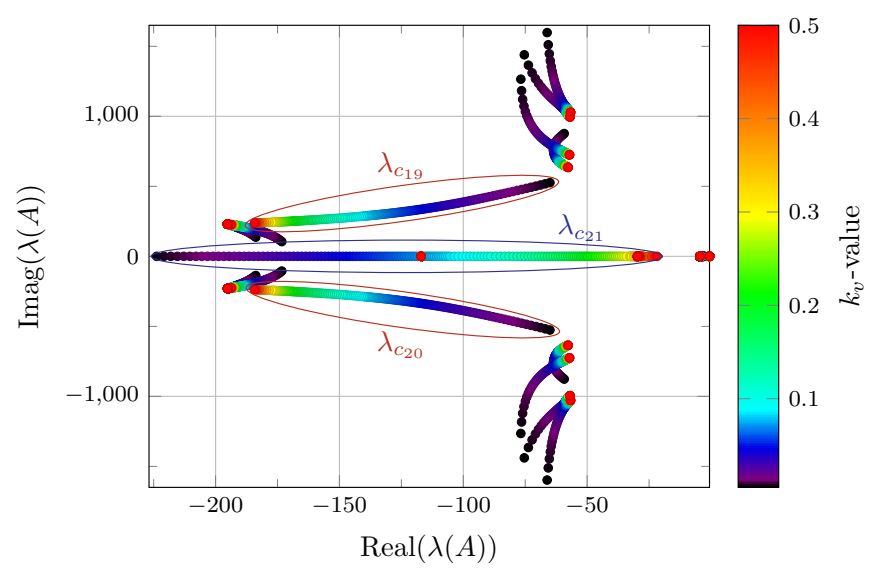

Fig. 10. Root locus of the state matrix A for voltage-droop parameters ranging from 0 to 0.5 p.u.

Figure 11 displays the results of an EMTP simulation of the DC voltage of the 5-terminal MTDC system for three 
different voltage-droop parameters, in the case of a wind-farm production loss. The figure shows that the time response of the DC voltage corresponds to the time response of the mode associated to the eigenvalue $\lambda_{c_{21}}$ as depicted in Figure 10. This demonstrates that the DC voltage dynamic is highly influenced by the voltage-droop parameters and that a judicious tuning of the voltage-droop parameters can make the DC voltage response time attain a desired value.

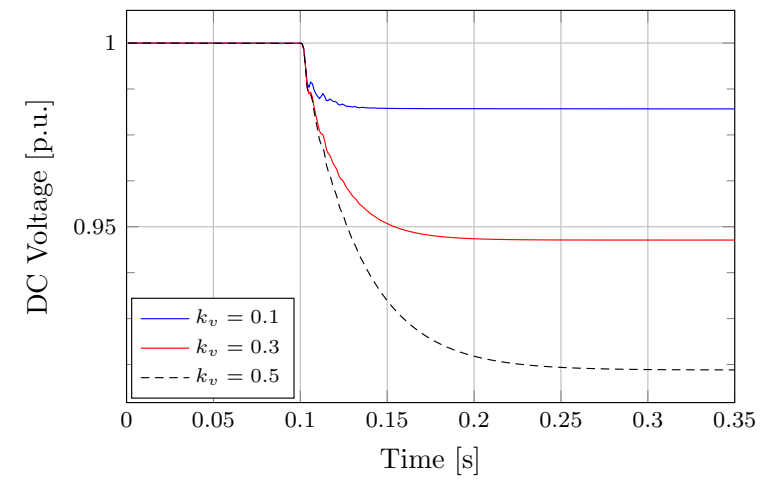

Fig. 11. DC voltage at the converter 1 terminal for different values of the voltage-droop parameter, for the same wind farm production loss.

\section{CONCLUSION}

In this paper, a methodology for small-signal analysis of multi-terminal HVDC systems has been proposed, involving the computation of the state-space model of each element of the HVDC grid separately and then combining them all into a global state-space representation for the entire MTDC system.

A comparison of time-domain simulations between a simplified and a more detailed model of a DC cable revealed that the shielded conductor damps the cable natural frequencies. A new cable model taking into account the coupling between the core and the screen of the cable has been proposed and validated. The state-space representation of this new model has been presented.

Finally, a modal analysis has been performed on the global state-space model of the MTDC system. The eigenvalue analysis together with a participation factor study of the eigenvectors enabled the identification of the MTDC system's modes. In particular, the existence of a single mode corresponding to the DC voltage dynamics of the system has been established. This mode has proved to be largely affected by the energy storage level of the DC grid, and to be predominantly influenced by the voltage-droop parameters of the converters, meaning that the DC voltage dynamic of the MTDC system can be imposed thanks to a judicious choice of the voltagedroop parameters.

VSCs data:

\section{APPENDIX}

$S_{n}=375$ MVA

$$
\begin{array}{ll}
U_{s_{n}}=640 \mathrm{kV} & V_{m_{n}}=230 \mathrm{kV} \\
R_{s}=1.22 \mathrm{E}-4 \text { p.u. } & C_{s}=30 \mu \mathrm{F}
\end{array}
$$

\begin{tabular}{|c|c|c|c|c|c|c|}
\hline DC line & 1 & 2 & 3 & 4 & 5 & 6 \\
\hline Length $(\mathrm{km})$ & 150 & 150 & 175 & 150 & 125 & 200 \\
\hline & \multirow{2}{*}{\multicolumn{3}{|c|}{$\begin{array}{l}l=3.740 \mathrm{mH} / \mathrm{km} \\
i_{\max }=2265 \mathrm{~A}\end{array}$}} & \multirow{2}{*}{\multicolumn{3}{|c|}{$c=0.247 \mu \mathrm{F} / \mathrm{km}$}} \\
\hline $\begin{aligned} r & =5.347 \mathrm{~m} \Omega / \mathrm{km} \\
g & =6.207 \mathrm{E}-8 \mathrm{~S} / \mathrm{km}\end{aligned}$ & & & & & & \\
\hline
\end{tabular}

$L_{s}=0.3$ p.u.

DC lines specifications:

\section{REFERENCES}

[1] N. Kirby, L. Xu, M. Luckett, and W. Siepmann, "HVDC transmission for large offshore wind farms," Power Engineering Journal, vol. 16, pp. 135-141, June 2002.

[2] N. Flourentzou, V. Agelidis, and G. Demetriades, "VSC-based HVDC power transmission systems: An overview," Power Electronics, IEEE Transactions on, vol. 24, pp. 592-602, March 2009.

[3] J. Beerten, S. Cole, and R. Belmans, "Modeling of multi-terminal vsc hvdc systems with distributed dc voltage control," Power Systems, IEEE Transactions on, vol. 29, pp. 34-42, Jan 2014.

[4] S. Akkari, M. Petit, J. Dai, and X. Guillaud, "Interaction between the voltage-droop and the frequency-droop control for multi-terminal HVDC systems," in AC and DC Power Transmission. 11th IET International Conference on, Birmingham, February 2015.

[5] T. M. Haileselassie, "Control of multi-terminal VSC-HVDC systems," Master's thesis, Norvegian University of Science and Technology, 2008.

[6] J. Beerten and R. Belmans, "Modeling and control of multi-terminal VSC HVDC systems," Energy Procedia, vol. 24, pp. 123-130, 2012.

[7] G. Kalcon, G. Adam, O. Anaya-Lara, S. Lo, and K. Uhlen, "Smallsignal stability analysis of multi-terminal VSC-based DC transmission systems," Power Systems, IEEE Transactions on, vol. 27, pp. 1818-1830, Nov 2012.

[8] S. Akkari, M. Petit, J. Dai, and X. Guillaud, "Modélisation, simulation et commande des systèmes VSC-HVDC multi-terminaux," in Symposium de Génie Électrique (SGE14), July 2014.

[9] T. Haileselassie, K. Uhlen, and T. Undeland, "Control of multiterminal HVDC transmission for offshore wind energy," in Nordic Wind Power Conference, September 2011.

[10] P. Rault, X. Guillaud, F. Colas, and S. Nguefeu, "Investigation on interactions between AC and DC grids," in PowerTech, 2013 IEEE Grenoble, pp. 1-6, June 2013.

[11] S. Akkari, J. Dai, M. Petit, and X. Guillaud, "Coupling between the frequency droop and the voltage droop of an AC/DC converter in an MTDC system," in PowerTech, 2015 IEEE Eindhoven, 2015.

[12] L. Kocar, J. Mahseredjian, and G. Olivier, "Weighting method for transient analysis of underground cables," Power Delivery, IEEE Transactions on, vol. 23, pp. 1629-1635, July 2008.

[13] P. Rault, Dynamic Modeling and Control of Multi-Terminal HVDC Grids. PhD thesis, Laboratory L2EP, University Lille Nord-de-France, 2014.

[14] F. W. Fairman, Linear Control Theory: the State-Space Approach. John Wiley \& Sons, 1998

[15] P. Kundur, Power System Stability and Control. McGraw-Hill, Inc, 1994. 